\title{
Perceived Organizational Support and Affective Commitment: A Demographic Analysis
}

\author{
Surjit Kaur ${ }^{1}$, Aneet $^{2}$ \\ ${ }^{1}$ (Research Scholar, I K Gujral Punjab Technical University, Jalandhar, India.) \\ ${ }^{2}$ (Director, GJIMT, I K Gujral Punjab Technical University, Jalandhar, India.)
}

\begin{abstract}
This descriptive research is conducted to study perceived organizational support and affective commitment with respect to demographic variables (gender, marital status, education etc.) and to study the relation between these variables. To realize this purpose the data on these variables was collected from 120 employees working in banking sectors with the help of standardized questionnaires. Statistical techniques of mean, standard deviation, correlation and regression and ANOVA were applied on data to test the hypothesis. Collected data was analyzed with the help of SPSS. The results highlight that perceived organizational support is positively related to affective commitment and POS accounts for $22 \%$ contribution to AC. The limitations of the study are discussed and future research areas are also highlighted.
\end{abstract}

Keywords: affective commitment, banks, employees, organizational commitment, organizational support

\section{Introduction}

Economy is changing fast and this has forced organizations to keep themselves embraced with all kinds of resources. Without doubt, human beings at work place are indispensible. Organizations cannot think of grabbing the unlimited and attractive opportunities without competent, skilled and committed workforce. Such employees are sure to perform better in both in-role and extra-role front. This thought lead to the conceptualization of this research. This paper intends to explore the relationship of affective commitment and perceived organizational support (POS).Organizational commitment (OC) is a state of being in which organizational members are bound by their actions and beliefs that sustain their activities and their own involvement in the organization [1]. According to Meyer et al., [2] organizational commitment as an attitude is "characterized by favorable positive cognitive and affective components about the organization". Further Meyer and Allen [3] defined organizational commitment as "a psychological state that characterizes the employee's relationship with the organization, and has implications for the decision to continue membership in the organization". Narteh [4] defined commitment as a felt state of employees' attachment to their organizations, including their willingness to internalize the values of the organization and abide by the rules and regulations therein. The author emphasized that organizational commitment should come willingly from the employee.

Organizational commitment consists of three dimensions viz. affective, continuance and normative commitment. Meyer and Allen [5] defined the first dimension, namely affective commitment (AC), "as positive feelings of identification with, attachment to and involvement in the work organization," and they defined continuance commitment as "the extent to which employees feel committed to their organization by virtue of the costs that they feel are associated with leaving". Allen and Meyer [6] defined normative commitment as "the employee's feelings of obligation to remain with the organization". This paper is limited to the study of affective commitment only.

Affective attachment is defined as "the relative strength of an individual's identification with and involvement in a particular organization" [7]. Affective commitment is also conceptualized as identification with the organization and internalization of organizational values [8]. In simple words, affective commitment is employee's positive emotional attachment to the organization [9]. Affectively committed employees are dedicated and loyal to their organization. They line up their personal goals with organizational goals and strive hard to achieve them. Such behavior ensures success and sustainability of an organization. Affective commitment is influenced by job challenge, goal clarity, goal difficulty, role clarity, peer cohesion, equity, personal importance, receptiveness by management, feedback, participation and dependability. Previous studies have identified affective commitment as a predictor of job satisfaction [10]; [11]; [12]; absenteeism, performance and turnover [13]; [14]; organizational citizenship behavior [15]; [16]; [17]; [18]; and also of POS [19].Eisenberger et al. [20] introduced the concept of organization's commitment to the employees and termed it as Perceived organizational support (POS). The concept of perceived organizational support is getting recognition in the management sphere of modern business world especially in the service sector. Eisenberger et al., [21] defined POS as "a general perception concerning the extent to which the organization values employees' general contributions and cares for their well-being". Further they added that a worker's perception of how an organization values him/her may be crucial for determining his/her attitudes benefiting the organization. In the 
words of Allen et al. [22] Perceived organizational support is "how much the organization values employees' contributions and cares about them". Perceived organizational support develops by meeting employees' socioemotional needs and showing readiness to reward employees' extra efforts and to give help that would be needed by employees to do their jobs better [20]. Perceived organizational support strengthens employees' effort in the organization, resulting in greater contribution in realization of organization's goals [20] The relationship of POS and AC finds its roots in Blau's social exchange theory and norm of reciprocity, which lay down that employees perceive organization as a source of social - emotional needs such as esteem, respect etc. besides being a source of tangible benefits (viz. pay, perks etc.). Perception of support creates an obligation in the minds of employees to reciprocate in the form of commitment toward the organization. Therefore, organizations endeavor to provide a supportive climate for their employees.

Gokul et al. [23] opined that perception regarding the kind of support required by employees from the organization to be supportive differs from one sector to another and from organization to another and thus it becomes the responsibility of the organization to understand employees' needs to feel supported. Organizations should provide a supportive climate to stimulate commitment and performance among employees. Tumwesigye [24] also suggested that organizations should create a positive working environment which ensures participation of employees in decision making, equitable social exchange, fair recognition \& reward system, to enhance perceived organizational support, which is vital to achieve organizational goals with committed employees.

\section{Review of literature}

Makanjee et al. [25] studied the effects of perceived organizational support on organizational commitment among diagnostic radiographers in South Africa. He opined that a radiographer's perception of support often dependents on day to day interactions and rightly found that employees perceive feedback and treatment of their direct supervisor as the support of upper management. The research revealed that the radiographers with low affective commitment were not involved in the decision making processes, top management decisions were not clearly communicated, they feel management had no interest in the well-being of their employees and they perceived unfairness in performance appraisal and promotion procedures, and their achievements unrecognized. An another study by Rhoades et al. [19]) found POS as positively related to temporal changes in affective commitment, suggestive of POS contribution to AC and not the vice- versa. The findings highlight the importance of favorable working conditions to enhance POS and thus enhance affective commitment.

Colakoglu et al. [26] investigated the relationship of organizational support with job satisfaction and dimensions of organizational commitment, and also analyzed the mediating effect of job satisfaction on the relationship between perceived organizational support and three dimensions of organizational commitment. The findings showed that perceived organizational support had a significant positive effect on job satisfaction, affective, normative and continuous commitment. Darolia et al. [27] conducted a study on regular skilled workers of National Fertilizer Ltd located in Punjab, India to investigate the extent to which organizational commitment, perceived organizational support, and work motivation predicts individual differences in job performance of workers. The results of the study highlighted a positive correlation between POS and three components of OC. POS correlates .36 ( $\mathrm{p}<.001)$ with affective commitment, .23 ( $\mathrm{p}<.01)$ with normative commitment and $.27(\mathrm{p}<.001)$ with continuance commitment.

UÇAR and ÖTKEN [28] studied the relationship of perceived organizational support with dimensions of organizational commitment and the mediating role of organization based self-esteem (OBSE) between these variables. They found a significant positive relationship of POS with affective \& normative commitment, but a negative relationship with continuance commitment. Caroline et al. [29] also studied the relationships between perceived organizational support (POS) and the dimensions of organizational commitment (i.e. affective, normative and continuance commitment), and further tested the moderating effect of locus of control and work autonomy on these relationships. The findings revealed that POS is positively and significantly correlated with affective and normative commitment and also found that locus of control and work autonomy moderates the relationship of POS and affective commitment. Several studies have also studied the impact of POS on AC. Like, Gokul et al. [23] studied the impact of perceived organizational support on affective commitment of employees working in petrochemical industry. The results revealed that perceived organizational support has a strong impact on affective commitment. Furthermore they expressed the views that if employees perceive that their organization is supportive, they become more dedicated and this in turn contributes to their emotional bonding with the organization. Tumwesigye [24] also found that affective commitment, continuance commitment, normative commitment, and overall organizational commitment are positively related to POS. POS explained $25 \%$ of the variance in affective commitment, $30 \%$ of the variance in normative commitment, 14 $\%$ of the variance in continuance commitment and $32 \%$ of the variance in overall organizational commitment. An earlier study by O'Driscoll \& Randall [30] conducted in New Zealand and Ireland found that POS accounted for substantial amount of variance in affective commitment. 
3.1 Objectives:

\section{Research Methodology}

1. To study the level of affective commitment and perceived organizational support of bank employees.

2. To study the relationship of demographic variables with affective commitment and perceived organizational support of bank employees.

3. To study the relationship of affective commitment and perceived organizational support of bank employees.

4. To study the effect of perceived organizational support on affective commitment of bank employees.

3.2 Hypotheses:

1. There will be no significant difference in the level of perceived organizational support among male and female employees.

2. There will be no significant difference in the level of perceived organizational support among married and unmarried employees.

3. There will be no significant difference in the level of perceived organizational support on the basis of educational qualification.

4. There will be no significant difference in the level of perceived organizational support on the basis of age.

5. There will be no significant difference in the level of perceived organizational support on the basis of experience.

6. There will be no significant difference in the level of affective commitment among male and female employees.

7. There will be no significant difference in the level of affective commitment among married and unmarried employees.

8. There will be no significant difference in the level of affective commitment on the basis of educational qualification.

9. There will be no significant difference in the level of affective commitment on the basis of age.

10. There will be no significant difference in the level of affective commitment on the basis of experience.

11. There is no relationship between affective commitment and perceived organizational support.

12. Perceived organizational support does not predict affective commitment.

\subsection{Method}

This descriptive study was conducted with the purpose of establishing a relationship between affective commitment and perceived organizational support. The population for the study was employees working in banks. The data for the study was collected from 120 employees working in banks. Perceived organizational support was measured using short version 8-item scale developed by Eisenberger et al. [20]. An example item includes "The organization really cares about my well-being." Affective commitment was measured using six items from organizational commitment scale of Meyer, Allen and Smith, [31]. An example item includes "I really feel as if this organization's problems are my own”. All the items were measured on a five point scale.

\subsection{Sample distribution}

Sample consisted of 120 employees working in banks. Majority (71\%) of respondents were male. Out of the total respondents $84 \%$ were married. $58 \%$ were of age group 30-40 yrs, followed by $24 \%$ in age group 2030 years, $15 \%$ in age group $40-50$ years and $3 \%$ in above 50 years age group. $34 \%$ of respondents were with a particular bank for less than two years.

\section{Results and Discussion}

Table 1 represents mean, standard deviation and correlation for the variables understudy. The mean of affective commitment is 4.71 which is above the average score of AC i.e. 2.5. This shows that affective commitment of bank employees is very high. Mean figure of POS (2.93) indicates that level of POS is above average. The results show that coefficient correlation is .48. This leads to the rejection of Null hypothesis (H11). Therefore it is proved that there exists a positive correlation between affective commitment and perceived organizational support. The result is in line with the earlier studies of Colakoglu et al. [26] and Darolia et al. [27]) which show that POS and AC are positively correlated.

Table 1. Mean, Standard Deviation and Pearson's Coefficient of Correlation

\begin{tabular}{|l|l|l|l|}
\hline Variables & Mean & Standard Deviation & $\begin{array}{l}\text { Coefficient of Correlation with perceived } \\
\text { organizational support (POS) }\end{array}$ \\
\hline AC & 4.71 & .92 & .48 \\
\hline POS & 2.93 & .78 & \\
\hline \multicolumn{2}{|l}{}
\end{tabular}

Source: Authors' compilation

Note: Level of Significance $5 \%$ 
Table 2. Regression Analysis for perceived organizational support as independent variable and affective commitment as dependent variable

\begin{tabular}{|c|c|c|c|}
\hline Variables & $\mathbf{R}^{2}$ & Adjusted $\mathbf{R}^{2}$ & Std. Error of Estimate \\
\hline POS & .23 & .22 & .81 \\
\hline
\end{tabular}

Table 2 shows the results of regression analysis for perceived organizational support as independent variable and affective commitment as dependent variable. The results of regression analysis indicates that $22 \%$ (Adjusted $\mathrm{R}^{2}=.22$ ) of affective commitment is explained by perceived organizational support. Hence Null hypothesis (H12) is rejected and therefore it is proved that POS predicts affective commitment but not significantly. The results of regression analysis are in consensus with the earlier studies of Tumwesigye [24] and O'Driscoll \& Randall [30] which found that POS is a predictor of affective commitment. Further the data was analyzed using t- test and ANOVA to test the significance of difference in the level of POS and AC across demographical variables. The results of table 3 show that there is significant difference in the level of POS among male and female employees because $\mathrm{p}$ value (.003) is less than the level of significance (.05). Therefore hypothesis (H1) is rejected, and it is inferred that male and female employees do have different perception of organizational support.

As far as marital status is concerned, there is no significant difference in the level of POS (p value > .05 ) among married and unmarried bank employees. Hence $\mathrm{H} 2$ is accepted. The study further found that there is no significant difference in the level POS on the basis of qualifications. It was found that UG and PG employees' perception of organizational support do not differ significantly. As shown in table 3, $\mathrm{p}$ value (.087) in case of educational qualification, is greater than level of significance, therefore null hypothesis (H3) is accepted. With the help of t- test (Table 3) it was found that difference in average score of AC is significant with respect to gender $(\mathrm{p}=.008)$, marital status $(\mathrm{p}=.001)$ and educational qualification $(\mathrm{p}=.00)$. Hence H6, H7, and $\mathrm{H} 8$ are rejected at 0.05 level of significance.

Table 3. Mean, Standard deviation and t value of Perceived organizational support and affective commitment on the basis of gender, marital status, and qualification

\begin{tabular}{|c|c|c|c|c|c|c|}
\hline Criterion variable & Demographical status & $\mathbf{N}$ & Mean & SD & $t$-value & $P$ value \\
\hline \multirow[t]{2}{*}{ POS } & Male & 85 & 2.6 & .87 & \multirow[t]{2}{*}{9.07} & \multirow[t]{2}{*}{.003} \\
\hline & Female & 35 & 3.1 & .52 & & \\
\hline \multirow[t]{2}{*}{$\mathrm{AC}$} & Male & 85 & 4.56 & .79 & \multirow[t]{2}{*}{7.23} & \multirow[t]{2}{*}{.008} \\
\hline & Female & 35 & 5.1 & 1.09 & & \\
\hline \multirow[t]{2}{*}{ POS } & Married & 101 & 2.93 & .84 & \multirow[t]{2}{*}{1.513} & \multirow[t]{2}{*}{.221} \\
\hline & Unmarried & 19 & 2.91 & .35 & & \\
\hline \multirow[t]{2}{*}{$\mathrm{AC}$} & Married & 101 & 4.69 & .89 & \multirow[t]{2}{*}{11.21} & \multirow[t]{2}{*}{.001} \\
\hline & Unmarried & 19 & 4.90 & 1.07 & & \\
\hline \multirow[t]{2}{*}{ POS } & UG & 48 & 3.12 & .64 & \multirow[t]{2}{*}{2.98} & \multirow[t]{2}{*}{.087} \\
\hline & PG & 72 & 3.09 & .84 & & \\
\hline \multirow[t]{2}{*}{$\mathrm{AC}$} & UG & 48 & 5.12 & 1.09 & \multirow[t]{2}{*}{16.56} & \multirow[t]{2}{*}{.000} \\
\hline & PG & 72 & 4.45 & .67 & & \\
\hline
\end{tabular}

One way ANOVA was further used to study the difference in the level of POS on the basis of age and experience. The findings of the study (Table 4) indicate that the perception of young and elderly employees do differ significantly. This is evident from the value of $\mathrm{p}(.04)$ which is lower than the assumed level of significance. Hence $\mathrm{H} 4$ is rejected. It can be inferred that elderly employees have high level of POS as compared to young employees. As shown in Table 4, mean values indicate that there exist a difference in the level of AC across different age groups and lower value of p (i.e. .00) indicates that this difference in the level of $\mathrm{AC}$ on the basis of age is highly significant and these results lead to the rejection of null hypothesis H9.

Table 4. ANOVA (One-way) for Perceived organizational support and affective commitment on the basis of

\begin{tabular}{|c|c|c|c|c|c|c|}
\hline Criterion variable & Age (in years) & $\mathbf{N}$ & Mean & SD & F -value & p value \\
\hline \multirow{4}{*}{$\begin{array}{l}\text { Perceived } \\
\text { Organizational } \\
\text { support }\end{array}$} & $20-30$ & 29 & 2.92 & .62 & \multirow[t]{4}{*}{2.86} & \multirow[t]{4}{*}{.04} \\
\hline & $30-40$ & 69 & 2.98 & .82 & & \\
\hline & $40-50$ & 18 & 2.57 & .73 & & \\
\hline & Above 50 & 4 & 3.72 & .87 & & \\
\hline \multirow{4}{*}{$\begin{array}{l}\text { Affective } \\
\text { Commitment }\end{array}$} & $20-30$ & 29 & 4.98 & .94 & \multirow[t]{4}{*}{6.24} & \multirow[t]{4}{*}{.001} \\
\hline & $30-40$ & 69 & 4.48 & .77 & & \\
\hline & $40-50$ & 18 & 4.90 & .87 & & \\
\hline & Above 50 & 4 & 6.08 & 1.61 & & \\
\hline
\end{tabular}

Source: Authors' compilation 
The findings of One way ANOVA (as shown in table 5) for POS in context of experience shows that $p$ value is .00 which is lower than the level of significance. Therefore null hypothesis (H5) is rejected and there is significant difference in the level of POS on the basis of experience. The employees whose experience is above 10 years have low perception of organizational support in comparison to employees with less experience. The results for affective commitment also shows that there is significant difference in the level of AC on the basis of experience $(\mathrm{p}<.05)$, which leads to the rejection of Null hypothesis $(\mathrm{H} 10)$.

Table 5: ANOVA (One - way) for Perceived organizational support and affective commitment on the basis of

\begin{tabular}{|c|c|c|c|c|c|c|}
\hline Criterion variable & Experience & $\mathbf{N}$ & Mean & SD & F -value & p value \\
\hline \multirow[t]{4}{*}{ POS } & $0-2$ & 41 & 3.09 & .70 & \multirow[t]{4}{*}{6.86} & \multirow[t]{4}{*}{.00} \\
\hline & $2-5$ & 13 & 3.27 & .48 & & \\
\hline & $5-10$ & 37 & 3.05 & .71 & & \\
\hline & Above 10 & 29 & 2.41 & .87 & & \\
\hline \multirow[t]{4}{*}{$\mathrm{AC}$} & $0-2$ & 41 & 5.05 & .91 & \multirow[t]{4}{*}{8.05} & \multirow[t]{4}{*}{.00} \\
\hline & $2-5$ & 13 & 5.11 & .57 & & \\
\hline & $5-10$ & 37 & 4.18 & .62 & & \\
\hline & Above 10 & 29 & 4.75 & 1.08 & & \\
\hline
\end{tabular}

\section{Conclusion}

The study was conducted to study the variables of affective commitment and perceived organizational support with respect to demographic variables viz. gender, marital status, age, qualification and experience and further to analyze the relationship between AC and POS. The findings of the study indicated that the variables are positively correlated and POS accounts for non significant contribution to affective commitment. The results have supported the hypothesis that marital status and qualification of employees do not affect the level of POS. Further it was found that perception of organizational support differ with gender, age and experience. Besides, demographic variables were found to be significantly affecting the level of affective commitment.

Though, the study provided with several findings which are useful for a manager to successfully achieve the objectives of the organization, yet, it's not free of limitations. The first limitation of this study is the sample size. The results can further be generalized by increasing the sample size of the study. This study is confined to banking sector only, so, findings cannot be replicated to other industries. Comparative studies of other sectors can also be undertaken in future research. As the finding indicated that POS is not a significant contributor to AC, other related variables like employee empowerment, management styles, justice, personal variables (personality, attitude etc.) culture and climate can be covered in further researches.

\section{Acknowledgement}

The authors are grateful to Punjab Technical University, Kapurthala, Punjab, India for their constant support to promote research and development and by being a source of encouragement to pursue this study.

\section{References}

[1]. Miller, and J. Lee, The people make the process: commitment to employees, decision-making and performance, Journal of Management, 27,2001, 163-189.

[2]. J.P. Meyer, and N.J. Allen, and I.R. Gellatly, Affective and continuance commitment to the organization: Evaluation of measures and analysis of concurrent and time-lagged relations, Journal of Applied Psychology, 75, 1990, 710-720.

[3]. J.P.Meyer, and N.J. Allen, A three-component conceptualization of organizational commitment, Human Resource Management Review, 1(1), 1991, 61-89.

[4]. B. Narteh, Internal marketing and employee commitment: Evidence from the Ghanaian banking industry Journal of Financial Services Marketing , 17(4), 2012, 284-300

[5]. J.P.Meyer, and N.J. Allen, Testing the 'side-bet' theory of organizational commitment: some methodological considerations, Journal of Applied Psychology, 69 (3), 1984, 372-378.

[6]. N. J. Allen, and J. P. Meyer, The measurement and antecedents of affective, continuance, and normative commitment to the organization, Journal of Occupational Psychology, 63, 1990, 1-18.

[7]. R. Mowday, R. M. Steers, and L.W. Porter, The measurement of organizational commitment, Journal of Vocational Behavior, 14, 1979, 224-247.

[8]. N. Beck, and J. Wilson, Development of affective organizational commitment: A crosssequental examination of change with tenure, Journal of Vocational Behaviour, 56, 2000, 114-136.

[9]. H.A. Patrick, and J. Sonia, Job satisfaction \& affective commitment, The IUP Journal of Organizational Behavior, 11(1), 2012, 136.

[10]. M. Jun, S. Cai, and H. Shin, TQM Practice in Maquiladora: Antecedents of Employee satisfaction and Loyalty, Journal of Operations Management, 24, 2006, 791-812.

[11]. H.C. Koh, and E.H.Y. Boo, The link between organizational ethics and job satisfaction: A study of managers in Singapore, Journal of Business Ethics, 29, 2001, 309-324.

[12]. H.C. Koh, and E.H.Y. Boo, Organizational ethics and employee satisfaction and commitment, Management Decision, 42(5), 2004, 677-693.

[13]. J.P.Meyer, and N.J. Allen, Commitment in the workplace (Thousand Oaks, CA: Sage Publications 1997) 
[14]. R.T. Mowday, L.W. Porter, L.W., \& Steers, R.M., Employee-organization linkages: The psychology of commitment, absenteeism, and turnover (New York: Academic Press, 1982)

[15]. J.P. Meyer, S.V. Paunonen, I.R. Gellatly, R.D. Goffin, and D.N. Jakson, Organizational commitment and job performance: it's the nature of commitment that counts. Journal of Applied Psychology, 74 (1), 1989, 152-56.

[16]. D.W. Organ, and K. Ryan, A meta-analytic review of attitudinal and dispositional predictors of organizational citizenship behavior, Personnel Psychology, 48(4), 1995, 775-802.

[17]. M. Wasko, \& S. Faraj, Why should I share? Examining knowledge contribution in electronic networks of practice. MIS Quarterly, 29 (1), 2005, 1-23.

[18]. H. Zeinabadi, Job satisfaction and organizational commitment as antecedents of organizational citizenship behavior (OCB) of teachers. Procedia Social and Behavioral Sciences, 5, 2010, 998-1003.

[19]. L. Rhoades, R. Eisenberger, and S. Armeli, Affective commitment to the organization: The contribution of perceived organizational support, Journal of Applied Psychology, 86(5), 2001, 825-836.

[20]. R. Eisenberger, R. Huntington, S. Hutchison, and D. Sowa, Perceived organizational support, Journal of Applied Psychology, 71, 1986, 500-507.

[21]. R. Eisenberger, P.M. Fasolo, and V. Davis-LaMastro, Effects of perceived organizational support on employee diligence, innovation, and commitment, Journal of Applied Psychology, 53, 1990, 51-59.

[22]. M.W. Allen, D.J. Armstrong, M.F. Reid, and C.K. Riemenschneider, Factors impacting the perceived organizational support of IT employees, Information and Management, 45, 2008, 556-563.

[23]. A.Gokul, G. Sridevi, \& P.T. Srinivasan, The relationship between perceived organizational support, work engagement and affective commitment, AMET International Journal of Management, 2012, 29-37

[24]. G. Tumwesigye, The relationship between perceived organizational support and turnover intentions in a developing country: The mediating role of organizational commitment, African Journal of Business Management, 4(6), 2010, 942-952.

[25]. C.R. Makanjee, Y.F. Hartzer, I.L. Uys, The effect of perceived organizational support on organizational commitment of diagnostic imaging radiographers, Radiography 12(2), 2006, 118-126.

[26]. U. Colakoglu, O. Culha , and H. Atay, The Effects of Perceived Organizational Support on Employees' Affective Outcomes: Evidence From The Hotel Industry Tourism and Hospitality Management, 16(2), 2010,125-150.

[27]. C.R. Darolia, P. Kumari, and S. Darolia, Perceived organizational support, work motivation, and organizational commitment as determinants of job performance, Journal of the Indian Academy of Applied Psychology 36(1), 2010, 69-78.

[28]. D. Uçar, and A.B. Ötken, Perceived Organizational Support and Organizational Commitment: The Mediating Role of Organization Based Self-Esteem, Journal of the Faculty of Dokuz. Eylul University Faculty of Economics and Administrative Sciences, 25(2), 2010, 85-110.

[29]. A. Caroline, V. Rousseau, E. M. Morin, Perceived organizational support and organizational commitment: The moderating effect of locus of control and work autonomy, Journal of Managerial Psychology, 22(5), 2007,479 - 495.

[30]. M.P. O'Driscoll, and D.M. Randall, Perceived organizational support, satisfaction with rewards, and employee job involvement and organizational commitment, Applied Psychology: An International Review, 48 (2), 1999, 197-209.

[31]. J.P. Meyer, and N.J. Allen, and C.A. Smith, Commitment to organizations and occupations: Extension and test of a threecomponent conceptualization, Journal of Applied Psychology, 78, 1993, 531-551. 